Original Research Paper

\title{
Perancangan Sistem Informasi Akademik SMPN I Tajurhalang
}

\author{
Agus Herdiyanto ${ }^{1}$, Normalisa ${ }^{1}$ \\ ${ }^{1}$ Program Studi Teknik Informatika, Fakultas Teknik, Universitas Pamulang, \\ Tanggerang Selatan, Indonesia.
}

Article History
Received:
13.10.2019
Revised:
09.11 .2019
Accepted:
03.12 .2019
*Corresponding Author:
Normalisa
Email:
dosen00377@unpam.ac.id

This is an open access article, licensed under: $\mathrm{CC}-\mathrm{BY}-\mathrm{SA}$
Abstrak: Perkembangan teknologi infomasi tidak lepas dari pesatnya perkembangan teknologi computer karena komputer merupakan media yang dapat memberikan kemudahan bagi manusia dalam menyelesaikan suatu pekerjaan. Perubahan dan dinamika masyarakat yang semakin cepat seiring dengan perkembangan jaman dan teknologi sehingga memerlukan kualitas informasi yang akurat, cepat dan tepat. Pengolahan data-data dalam bentuk berkas yang dilakukan oleh divisi tata usaha masih dimungkinkan hilang sehingga menyulitkan divisi tata usaha ketika akan membuat laporan hasil belajar siswa yang baru. Permasalahan yang sama juga terjadi dalam penerimaan informasi akademik karena pengolahan data laporan yang berjalan dilakukan dengan cara penginputan komputerisasi yang masih lokal dan manual kemudian file menjadi dokumen print out yang disimpan dalam berkas-berkas dilemari penyimpanan. Sistem pada penelitian ini menggunakan bahasa pemrograman PHP dikarenakan PHP adalah salah satu bahasa server-side yang didesain khusus untuk aplikasi web yang mana PHP dapat disisipkan di antara bahasa HTML.

Kata Kunci: PHP, Sistem Informasi, Web,

Academic Information System Design for SMPN I Tajurhalang

Abstract: The development of information technology can not be separated from the rapid development of computer technology because computers are media that can provide convenience for humans in completing a job. Changes and dynamics of society are increasingly fast along with the development of the era and technology so that it requires the quality of information that is accurate, fast and precise. Data processing in the form of files carried out by the administrative division is still possible to be lost, making it difficult for the administrative division when it will make a report on the learning outcomes of new students. The same problem also occurs in the reception of academic information because the processing of report data that is running is done by inputting a computerized data that is still local and manually then the file becomes a print out document that is stored in files in a storage cabinet. The system in this study uses the PHP programming language because PHP is a server-side language specifically designed for web applications where PHP can be inserted between HTML languages

Keywords: Information System, PHP, Web. 


\section{Pendahuluan}

Sistem informasi dan teknologi komputer berkembang sangat pesat sejalan dengan besarnya kebutuhan terhadap informasi. Perkembangan teknologi infomasi tidak lepas dari pesatnya perkembangan teknologi computer karena komputer merupakan media yang dapat memberikan kemudahan bagi manusia untuk menyelesaikan suatu pekerjaan. Perubahan dan dinamika masyarakat yang semakin cepat seiring dengan perkembangan jaman dan teknologi sehingga memerlukan kualitas informasi yang akurat, cepat dan tepat [1].

Berdasarkan hasil observasi, SMP Negeri I Tajurhalang masih menggunakan sistem pendataan manual ketika membuat laporan serta informasi akademik. Hal tersebut membuat pembaharuan informasi masih dilakukan secara manual yang akan menyebabkan kemungkinan adanya keterlambatan pengiriman laporan dan kesalahpahaman antar murid dan guru serta penyampaian orangtua wali kepada peserta didik.

Pengolahan data dengan bentuk berkas yang dilakukan oleh divisi tata usaha masih dimungkinkan hilang sehingga menyulitkan divisi tata usaha ketika akan membuat laporan hasil belajar siswa yang baru. Permasalahan yang sama juga terjadi pada penerimaan informasi akademik karena pengolahan data laporan yang berjalan dilakukan dengan cara penginputan komputerisasi yang masih lokal dan manual kemudian file menjadi dokumen print out yang disimpan dalam berkas-berkas di lemari penyimpanan.

Berdasarkan permasalahan yang telah diuraikan, maka diperlukan suatu sistem untuk membantu dalam proses pendataan terkomputerisasi sehingga dapat membantu informasi dalam membuat laporan informasi akademik sekolah sehingga perlu dilakukan penelitian mengenai "Perancangan Aplikasi Sistem Informasi Akademik Berbasis Web Pada SMPN I Tajurhalang". Penelitian yang dilakukan mempunyai suatu tujuan, antara lain:

1. Mempermudah pihak sekolah untuk mencari informasi data sekolah,

2. Mempermudah sekolah pengelolaan data dan laporan karena sudah terintegrasi dengan database sehingga mengurangi kerangkapan data,

3. Mengurangi keterlambatan pengiriman laporan akademik sekolah yang berjalan di sekolah.

\section{Tinjauan Pustaka}

\subsection{Pengertian Akademik Sekolah}

Akademik sekolah adalah suatu administrasi sekolah sebagai pengelola dan bertanggung jawab pada pengumpulan, pengelolaan, pemrosesan dan penyimpanan data sebagai usaha untuk pengelola database yang baik untuk kepentingan sekolah pribadi maupun untuk kegiatan dinas seperti supervisi [2]. Administrasi sekolah menengah yang tertib dan teratur sangat diperlukan untuk meningkatkan kemampuan pengelolaan pendidikan.

\subsection{Sistem Informasi Akademik}

Sistem informasi akademik adalah suatu sistem yang mengolah data-data akademik pada suatu instansi pendidikan baik formal maupun informal dari tingkat dasar sampai tingkat perguruan tinggi. Secara umum data-data yang diolah dalam sistem informasi akademik meliputi data guru, data siswa, data mata pelajaran dan jadwal mengajar dan data-data lain yang bersifat umum berdasarkan kebutuhan masing- masing lembaga pendidikan. Secara singkat sistem informasi akademik dapat diartikan aplikasi untuk membantu memudahkan pengelolaan data-data dan informasi yang berkaitan dengan instansi pendidikan.

Secara teori, penerapan sebuah sistem informasi memang tidak harus menggunakan komputer dalam kegiatannya. Tetapi pada prakteknya tidak mungkin sistem informasi yang sangat kompleks itu dapat berjalan dengan baik jika tanpa adanya komputer. Sistem informasi merupakan sistem pembangkit informasi. Dengan integrasi yang dimiliki antar subsistemnya, sistem informasi akan mempu menyediakan informasi yang berkualitas, tepat, cepat dan akurat sesuai dengan manajemen yang mebutuhkannya [3].

\subsection{Pengenalan Internet}

Internet singkatan dari interconnection-networking adalah seluruh jaringan komputer yang saling terhubung menggunakan stardar sistem global Transmission Control Protocol / Internet Protocol Suite (TCP/IP) sebagai protokol pertukaran paket (packet switching communication protocol) untuk melayani milliaran pengguna diseluruh dunia. Transmission Control Protocol (TCP) adalah suatu protokol yang berada dilapisan tranpost (baik itu dalam tujuh lapis model referensi OSI atau model 
DARPA) yang berorientasi sambungan (connection-oriented) dan dapat diandalkan. Sedangkan Internet Protocol (IP) adalah protokol lapisan jaringan (network layer dalam OSI reference model) atau protokol lapisan internetwork yang digunakan oleh protokol TCP/IP untuk melakukan pengalamatan dan routing paket data antar host-host di jaringan komputer berbasis TCP/IP. Versi IP yang banyak digunakan IP versi 4 (IPv4) yang didefinisikan pada RFC 791 dan dipublikasikan pada tahun 1981, tetapi akan digantikan oleh IP versi 6 pada beberapa waktu yang akan datang. Pengaruh internet tidak hanya terhadap bidang teknik komunikasi komputer saja tetapi, terhadap masalah sosial misalnya dengan menggunakan alat-alat bantu online untuk mencapai bisnis elektronik (e-commerce), kepemilikan informasi dan interaksi dengan masyarakat [4].

\subsection{Web Server}

Web server adalah sebuah bentuk server yang khusus digunakan untuk menyimpan halaman website atau homepage. Komputer dapat dikatakan web server jika komputer tersebut memiliki suatu program server yang disebut Personal Web Server (PWS). Menurut Syafri [5] macam-macam web server antara lain :

1. Apache (Open Source)

2. Xitami

3. Iis

4. PWS (Personal Web Server)

Website (Situs Web) merupakan alamat (URL) yang berfungsi sebagai tempat penyimpanan data dan informasi dengan berdasarkan topik tertentu situs atau web dapat dikategorikan menjadi 2 yaitu :

1. Web Statis

2. Web Dinamis

\subsection{Pengenalan PHP}

PHP adalah bahasa pemrograman script yang paling banyak dipakai saat ini. PHP banyak dipakai untuk memrogram situs web dinamis, walaupun tidak tertutup kemungkinan digunakan untuk pemakain lain. Contoh terkenal dari aplikasi PHP adalah forum (phpBB) dan mediawiki (software di belakang wikipedia). PHP juga dapat dilihat sebagai pilihan lain dari ASP.NET/C\#/VB.NET Microsoft, ColdFusion Macromedia, JSP/Java Sun Microsystems, dan CGI/Perl. Contoh aplikasi lainnya yang lebih kompleks berupa CMS yang dibangun menggunkan PHP adalah Mambo, Joomla, Postnuke, Xaraya, dan lain lain.

Rasmus Lerdorf merupakan seorang programmer yang menciptakan PHP pada tahun 1994. PHP adalah salah satu server side yang dirancang khusus untuk aplikasi web. PHP disisipkan diantara bahasa HTML dan karena bahasa server side, maka bahasa PHP akan dieksekusi di server, sehingga yang dikirimkan kebrowser adalah hasil jadi dalam bentuk HTML, dan kode PHP tidak akan terlihat. PHP termasuk Open Source Product. Jadi, dapat diubah source code dan mendistribusikannya secara bebas.

Selanjutnya Rasmus merilis kode sumber tersebut untuk umum dan menanmakan PHP/FI. Dengan perilisan kode sumber ini menjadi open source, maka banyak programer yang tertarik untuk ikut mengembangkan PHP. Pada november 1997, dirilis PHP/FI 2.0. Pada rilis ini interpreter PHP sudah diimplementasikan dalam program C. Dalam rilis ini disertakan juga modul-modul ekstensi yang meningkatkan kemampuan PHP/FI secara signifikan. Pada tahun 1997, sebuah perusahaan bernama Zend menulis ulang interpreter PHP menjadi lebih bersih, lebih baik, dan lebih cepat. Kemudian pada juni 1998, perusahaan tersebut merilis interpreter baru untuk PHP dan meresmikan rilis tersebut sebagai PHP 3.0 dan singkatan PHP dirubah menjadi akronim berulang PHP: Hypertext Preprocessing.

Pada pertengahan tahun 1999, Zend merilis interpreter PHP baru dan rilis tersebut dikenal dengan PHP 4.0. PHP 4.0 adalah versi PHP yang paling banyak dipakai pada awal abad ke-21. Versi ini banyak dipakai disebabkan kemampuannya untuk membangun aplikasi web kompleks tetapi tetap memiliki kecepatan dan stabilitas yang tinggi.

\subsection{Konsep dasar PHP}

Kode PHP diawali dengan tanda lebih kecil (). Pemisah antar instruksi adalah tanda titik koma (;). Untuk membuat atau menambahkan komentar, standar penulisan adalah $/ *$ komentar*////komentar dan \#komentar. Pada penulisan script PHP ada dua cara yang sering digunakan yaitu Embedded Script dan 
Non-Embedded Script.

\subsection{Pengenalan MySQL}

MySQL adalah sebuah implementasi dari sistem manajemen basis data relasional (RDBMS) yang didistribusikan secara gratis dibawah lisensi GPL (General Public License). Setiap pengguna dapat secara bebas menggunakan MySQL namun dengan batasan perangkat lunak tersebut tidak boleh dijadikan produk turunan yang bersifat komersial. MySQL sebenarnya merupakan turunan salah satu konsep utama dalam basis data yang telah ada. Sebelumnya SQL (Structured Query Language) adalah sebuah konsep pengoperasian basisdata, terutama untuk pemilihan atau seleksi dan pemasukan data yang memungkinkan pengoperasian data dikerjakan dengan mudah secara otomatis.

Kehandalan suatu sistem basis data (DBMS) dapat diketahui dari cara kerja pengoptimasinya dalam melakukan proses perintah-perintah SQL yang dibuat oleh penggunan maupun programprogram aplikasi yang memamfaatkannya. Sebagai peladen basisdata, MySQL mendukung operasi basis data transaksional maupun operasi basisdata non-transaksional. Pada modus operasi nontransaksional, MySQL dapat dikatakan unggul dalam hal unjuk kerja dibandingkan perangkat lunak peladen basisdata kompetitor lainnya. Namun pada modus non-transaksional, tidak ada jaminan atas reabilitas terhadap data yang tersimpan, karenanya modus non-transaksional hanya cocok untuk jenis aplikasi yang tidak membutuhkan realibilitas data seperti aplikasi blogging berbasis web (wordpress), $C M S$, dan sejenisnya.

\subsection{Pengenalan Notepad ++}

Notepad ++ adalah sebuah penyunting teks dan penyunting kode sumber yang berjalan disistem operasi windows. Notepad ++ menggunkan komponen scintila untuk dapat menampilkan dan menyunting teks dan berkas kode sumber berbagai bahasa pemrograman. Notepad ++ didistribusikan sebagai perangkat lunak bebas. Proyek ini dilayani oleh SourceForge.net, telah diunduh lebih dari 27 juta kali dan dua kali memenangkan penghargaan SourceForge Community Choice Award for Best Developer Tool. Didukung dalam hal ini adalah dimengerti dan diterjemahkan menjadi teks oleh Notepad ++. Misalnya pada $\mathrm{C}++$, fungsi-fungsinya akan dimasukkan kedalam daftar fungsi dan katakatanya akan berubah warna sesuai dengan makna kata tersebut di $\mathrm{C}++[6]$.

\subsection{XАMPP}

XAMPP dikembangkan oleh Apache Friends yang merupakan sebuah website non-komersial yang bertujuan untuk mempromosikan web server Apache. XAMPP di temukan pada tahun 2002 oleh Kai' Oswald' Seidler dan Kay Vogelgesang [7].

\subsection{Unified Modeling Language}

Unified Modeling Language (UML) merupakan salah satu alat bantu yang dapat digunakan dalam bahasa pemograman yang berorientasi objek, saat ini UML akan mulai menjadi standar masa depan bagi industri pengembangan sistem/perangkat lunak yang berorientasi objek karena pada dasarnya UML digunakan oleh banyak perusahaan raksasa seperti IBM, Microsoft, dan sebagainya. Berdasarkan beberapa pendapat yang dikemukakan diatas dapat ditarik kesimpulan bahwa UML adalah sebuah bahasa yang berdasarkan grafik atau gambar untuk menvisualisasikan, menspesifikasikan membangun dan pendokumentasian dari sebuah sistem pengembangan perangkat lunak berbasis Object Oriented programming.

\subsection{Unit Testing}

\subsubsection{Black Box Testing}

Terfokus pada apakah unit program memenuhi kebutuhan (requirement) yang disebutkan dalam spesifikasi. Pada black box testing, cara pengujuan hanya dilakukan dengan menjalankan atau mengeksekusi unit atau modul, kemudian diamati apakah hasil dari unit itu sesuai dengan proses bisnis yang diinginkan. Jika ada unit yang tidak sesuai outputnya maka untuk menyelesaikannya, diteruskan pada pengujian yang kedua, yaitu white box testing [8].

\subsubsection{White-Box Testing}

White box testing adalah cara pengujian dengan melihat kedalam modul untuk meneliti kode-kode program yang ada, dan menganalisa apakah ada kesalahan atau tidak. Jika ada modul yang menghasilkan output yang tidak sesuai dengan proses bisnis yang dilakuka, maka baris-baris program, 
vriabel, dari parameter yang terlibat pada unit tersebut akan dicek satu persatu dan diperbaiki, kemudian di-compile ulang [8].

\section{Metode Penelitian}

\subsection{Analisa Sistem}

Analisa sistem adalah panguraian dari suatu sistem informasi yang utuh ke dalam bagian-bagian komponennya dengan maksud untuk mengidentifikasikan dan mengevaluasi permasalahan permasalahan, kesempatan-kesempatan, hambatan-hambatan yang terjadi dan kebutuhan-kebutuhan yang diharapkan sehingga dapat diusulkan perbaikan-perbaikan [9]. Tahap analisis sistem ini merupakan tahap yang sangat penting karena kesalahan pada tahap selanjutnya, sehingga permasalahan itu dapat diperbaiki. Tahap analisis sistem ini berguna untuk menemukan kelemahankelemahan sehingga dapat diusulkan perbaikannya setelah melakukan pengumpulan data-data.

\subsection{Analisa Sistem Saat Ini}

Saat ini proses sistem akademik yang sedang berjalan pada Sekolah Menengah Pertama Negeri I Tajurhalang ini merupakan sistem akademik yang sifatnya masih manual artinya semua data baik itu data siswa, data guru dan data nilai siswa disimpan di suatu buku besar biodata siswa dan biodata guru yang media penyimpanannya kurang efektif karena ketidakadaannya sistem database akademik. Penjelasan sistem yang berjalan dapat diuraikan sebagai berikut:

1. Setiap tahun penerimaan siswa baru SMP Negeri I Tajurhalang yang mendaftar dilakukan secara manual. Hal ini tidak efesien setiap pendaftar memerlukan waktu yang cepat.

2. Penerimaan siswa baru semuanya dilaporkan kepada kepala sekolah.

3. Setiap bulan laporan data jumlah siswa keseluruhannya dilaporkan kepada kepala sekolah.

4. Pembuatan laporan baik itu daftar siswa, daftar guru dilakukan dibuku besar biodata siswa dan biodata guru.

5. Ketidakadaannya database akademik khususnya yang mengolah data siswa dan data guru yang mengajar sehingga dalam pembuatan laporan dan pencarian data harus memakan waktu yang begitu lama, karena harus membuka arsip demi arsip.

\subsection{Analisa Sistem yang Berjalan}

Analisa sistem berjalan merupakan langkah awal untuk mengidentifikasikan permasalahan dan faktorfaktor lainnya yang berhubungan dengan sistem yang akan dibuat. Analisa sistem yang sedang berjalan dapat dilakukan dengan mengumpulkan data-data dan prosedur-prosedur yang terjadi pada instansi yang bersifat masih sistem lama atau konvesional. Use Case dalam proses pendaftaran sistem yang berjalan disajikan pada Gambar 1 .

Gambar 1 menjelaskan tentang proses sistem berjalan saat ini. Bagian tata usaha memberikan formulir kepada guru dan siswa, kemudian formulir tersebut diisi oleh guru dan siswa, setelah guru dan siswa mengisi data formulir tersebut, lalu guru dan siswa yang bersangkutan memberikan formulir yang telah diisi kepada bagian tata usaha. Setelah itu, bagian tata usaha menyimpan data-data tersebut ke alam pengarsipan sekolah. Apabila guru ataupun siswa yang ingin melihat datanya untuk dirubah, maka bagian admin/TU akan mencari di arsip sekolah yang telah tersimpan dilemari sekolah. Pencarian arsip ini membutuhkan waktu yang cukup lama, karena harus dicari satu persatu secara manual. Seorang admin/TU berkewajiban untuk memberikan laporan data guru dan data siswa kepada kepala sekolah.

\subsection{Analisa Masalah}

Berdasarkan pengamatan yang dilakukan di SMP Negeri I Tajurhalang, sistem pengolahan database akademik yang dipakai masih menggunakan cara manual (non komputerisasi), maka kendala-kendala yang dihadapi adalah:

1. Kurang akuratnya data dan informasi yang diperoleh.

2. Selalu terjadi keterlambatan informasi dari data yang diinginkan.

3. Memerlukan waktu yang lama dalam pengerjaan ketika mengolah data tersebut.

4. Sering adanya kesalahan penulisan dan perhitungan database siswa dan guru sehingga informasi yang ada tidak sesuai. 


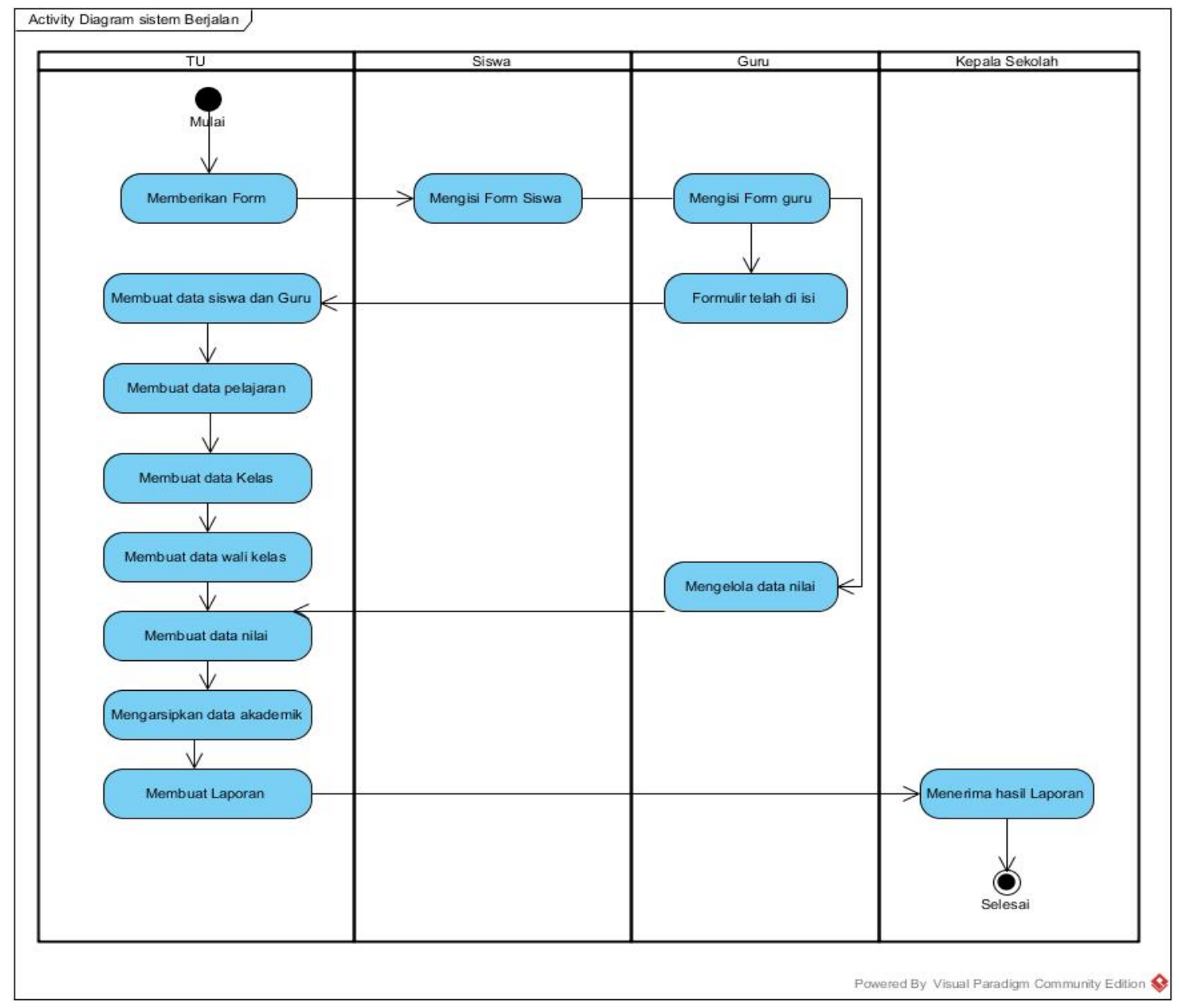

Gambar 1. Activity Diagram Sistem Berjalan

\subsection{Perancangan Sistem Usulan}

Setelah melakukan analisa terhadap masalah yang ada pada SMP Negeri I Tajurhalang, tentang sistem informasi akademik maka peneliti mencoba memberikan alternatif pemecahan masalah dengan membuat suatu rancangan sistem yang baru yaitu membuat sistem informasi akademik secara online yang dibuat dengan menggunakan bahasa pemograman PHP dan database MySQL. Diharapkan dengan adanya sistem ini dapat memperbaiki sistem yang lama untuk menyampaikan informasi ke sekolah tentang data siswa, nilai dan pembayaran, memberikan fasilitas kepada guru untuk input nilai siswa/i secara langsung, memberikan kemudahan untuk admin sekolah dalam membuat laporan administrasi sekolah. Oleh karena itu guru, siswa dan admin sangat terbantu dalam mendapatkan informasi yang diinginkan pada sekolah SMP Negeri I Tajurhalang.

\subsection{Perancangan Basis Data}

Pembuatan aplikasi Sistem Informasi Akademik pada SMP Negeri 1 Tajurhalang yaitu dengan menggunakan database. Perancangan database terdiri dari Entity Relationship Diagram (ERD), Tansformasi Entity Relationship Diagram (ERD) ke Logical Record Structure (LRS), dan perancangan Logical Record Structure (LRS).

\subsubsection{Perancangan Basis Data}

Pembuatan aplikasi Sistem Informasi Akademik pada SMP Negeri 1 Tajurhalang yaitu dengan menggunakan database. Perancangan database terdiri dari Entity Relationship Diagram(ERD), Tansformasi Entity Relationship Diagram (ERD) ke Logical Record Structure (LRS), dan perancangan Logical Record Structure (LRS). 
Agus Herdiyanto, Normalisa.

Perancangan Sistem Informasi Akademik SMPN I Tajurhalang.

Journal of Engineering, Technology \& Applied Science, vol. 1, no. 1, pp. 1-18, December 2019. DOI: 10.36079/lamintang.jetas-0101.90

\subsubsection{Spesifikasi Basis Data}

Berikut adalah tabel-tabel yang diperlukan untuk membuat Sistem Informasi Akademik:

1. Siswa

Spesifikasi data siswa disajikan pada Tabel 1.

Penjelasan isi dari Tabel 1 adalah:
Fungsi
: digunakan untuk menampung data siswa
Nama tab
: siswa
Isi
: data siswa

Tabel 1. Basis Data: Siswa

\begin{tabular}{|c|c|c|c|c|}
\hline No & Nama Field & Type & Size & Keterangan \\
\hline 1 & *ID_Siswa & Varchar & 20 & primary key \\
\hline 2 & Nama_Lengkap & char & 50 & - \\
\hline 3 & Agama & char & 20 & - \\
\hline 4 & Tempat_Lahir & char & 20 & - \\
\hline 5 & Tanggal_Lahir & date & YYYY-MM-DD & - \\
\hline 6 & Alamat & text & 100 & - \\
\hline 7 & Jenis_Kelamin & enum & $(\mathrm{lk}, \mathrm{pr})$ & - \\
\hline 8 & Nama_Ayah & char & 20 & - \\
\hline 9 & Pekerjaan_Ayah & char & 20 & - \\
\hline 10 & No_HP_Orang_Tua & Varchar & 20 & - \\
\hline 11 & Status & char & 20 & - \\
\hline 12 & Username & Varchar & 50 & - \\
\hline 13 & Password & Varchar & 50 & - \\
\hline 14 & ID_Kelas & Int & 11 & Foreign Key \\
\hline 15 & Jurusan & Varchar & 20 & - \\
\hline
\end{tabular}

2. Kelas

Spesifikasi data kelas disajikan pada Tabel 2.

Penjelasan isi dari Tabel 2:

Fungsi : digunakan untuk menampung data kelas

Nama tabel : kelas

Isi : data kelas

Tabel 2. Basis Data: Kelas

\begin{tabular}{|r|l|l|c|c|}
\hline \multicolumn{1}{|c|}{ No } & Nama Field & Type & Size & Keterangan \\
\hline 1 & *ID_Kelas & Int & 11 & Primery Key \\
\hline 2 & Nama_Kelas & Char & 50 & - \\
\hline
\end{tabular}

3. Mata Pelajaran

Spesifikasi data mata pelajaran disajikan pada Tabel 3.

Penjelasan Tabel 3 adalah:

Fungsi : digunakan untuk menampung data mata pelajaran

Nama tabel : mata_pelajaran

Isi $\quad$ : data mata pelajaran

Tabel 3. Basis Data: Mata Pelajaran

\begin{tabular}{|r|l|l|c|c|}
\hline No & Nama Field & Type & Size & Keterangan \\
\hline 1 & *ID_Mapel & Int & 11 & Primary Key \\
\hline 2 & Nama_Mapel & Char & 20 & - \\
\hline 3 & KKM & double & 2,3 & - \\
\hline
\end{tabular}


Agus Herdiyanto, Normalisa.

Perancangan Sistem Informasi Akademik SMPN I Tajurhalang.

4. Nilai

Spesifikasi data nilai pelajaran disajikan pada Tabel 4.

Penjelasan Tabel 4:

$\begin{array}{ll}\text { Fungsi } & \text { : digunakan untuk menampung data mata nilai } \\ \text { Nama tabel } & \text { : niai } \\ \text { Isi } & \text { : data nilai }\end{array}$

Tabel 4. Basis Data: Nilai

\begin{tabular}{|r|l|l|c|c|}
\hline No & Nama Field & Type & Size & Keterangan \\
\hline 1 & *ID_Nilai & Int & 11 & Primery Key \\
\hline 2 & Jenis_nilai & Char & 50 & - \\
\hline 3 & Nilai & Double & 2,3 & \\
\hline 4 & ID_Mapel & Int & 11 & foreign_key \\
\hline 5 & ID_siswa & Varchar & 20 & foreign_key \\
\hline 6 & ID_Tekep & Varchar & 20 & foreign_key \\
\hline
\end{tabular}

5. Pembayaran

Spesifikasi data pembayaran disajikan pada Tabel 5

Penjelasan Tabel 5:

Fungsi : digunakan untuk menampung data pembayaran

Nama tabel : pembayaran

Isi : data pembayaran

Tabel 5. Basis Data: Pembayaran

\begin{tabular}{|r|l|l|c|c|}
\hline No & Nama Field & Type & Size & Keterangan \\
\hline 1 & *ID_Bayar & Int & 11 & Primery Key \\
\hline 2 & Jenis_pembayaran & Char & 50 & - \\
\hline 3 & Nominal & Varchar & 100 & \\
\hline 4 & Tanggal & Date & YYYY-MM-DD & \\
\hline 5 & ID_siswa & Varchar & 20 & foreign key \\
\hline 6 & ID_Tekep & Varchar & 20 & foreign key \\
\hline
\end{tabular}

6. Tenaga Kependidikan

Spesifikasi data tenaga kependidikan disajikan pada Tabel 6.

Penjelasan Tabel 6:

Fungsi : digunakan untuk menampung data tenaga kependidikan

Nama tabel : tenaga kependidikan

Isi : data tenaga kependidikan

Tabel 6. Basis Data: Tenaga Kependidikan

\begin{tabular}{|r|l|l|c|c|}
\hline No & Nama Field & Type & Size & Keterangan \\
\hline 1 & *ID_Tekep & Varchar & 20 & Primary Key \\
\hline 2 & Nama & Char & 50 & - \\
\hline 3 & Alamat & Text & 100 & - \\
\hline 4 & Telepon & Varchar & 20 & - \\
\hline 5 & Username & Varchar & 50 & - \\
\hline 6 & Password & Varchar & 50 & - \\
\hline 7 & ID_jabatan & Int & 11 & foreign key \\
\hline
\end{tabular}


Agus Herdiyanto, Normalisa.

Perancangan Sistem Informasi Akademik SMPN I Tajurhalang.

Journal of Engineering, Technology \& Applied Science, vol. 1, no. 1, pp. 1-18, December 2019. DOI: 10.36079/lamintang.jetas-0101.90

7. Jabatan

Spesifikasi data jabatan disajikan pada Tabel 7.

Penjelasan Tabel 7:

Fungsi : digunakan untuk menampung data jabatan

Nama tabel : jabatan

Isi $\quad$ : data jabatan

Tabel 7. Basis Data: Jabatan

\begin{tabular}{|r|l|l|c|c|}
\hline \multicolumn{1}{|c|}{ No } & Nama Field & Type & Size & Keterangan \\
\hline 1 & *ID_Jabatan & Int & 11 & Primery Key \\
\hline 2 & Jabatan & char & 50 & - \\
\hline
\end{tabular}

\subsection{Unified Modelling Language}

Unified Modelling Language (UML) adalah sebuah "bahasa" yg telah menjadi standar dalam industri untuk visualisasi, merancang dan mendokumentasikan sistem piranti lunak [10]. UML menawarkan sebuah standar untuk merancang model sebuah sistem. Diagram-diagram yang digunakan dalam perancangan visualisasi sistem yang akan diterapkan dalam sistem baru tentang Sistem Informasi Akademik meliputi:

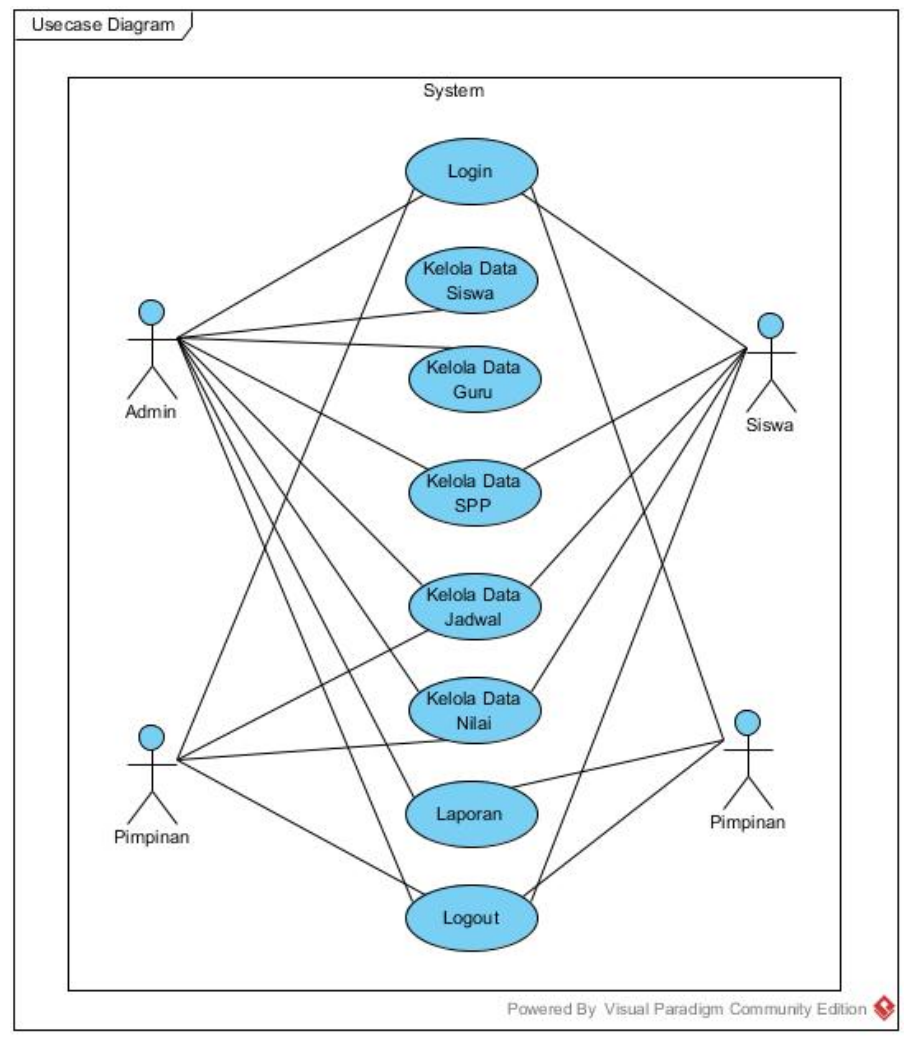

Gambar 2. Use Case Diagram Sistem Informasi Akademik

\subsubsection{Use Case Diagram}

Use case diagram merupakan gambaran interaksi diantara komponen-komponen aplikasi yang memperkenalkan bagaimana interaksinya dengan pengguna. Use case diagram sistem informasi akademik disajikan pada Gambar 2.

Berdasarkan Gambar 2 maka dapat dijelaskan urutan kegiatan yang dilakukan system dan actor. Deskripsi Use case diagram sistem usulan admin disajikan pada Tabel 8. 
Tabel 8. Deskripsi Use Case Diagram Sistem Usulan Admin

\begin{tabular}{|l|l|l|}
\hline \multicolumn{1}{|c|}{ Aktor } & \multicolumn{1}{|c|}{ Nama Use Case } & \multicolumn{1}{c|}{ Keterangan } \\
\hline Admin & Login & Admin harus login terlebih dahulu untuk mengakses aplikasi. \\
\hline Admin & Kelola Data Siswa & $\begin{array}{l}\text { Admin mengelola data siswa yang dapat memproses input, } \\
\text { edit dan hapus }\end{array}$ \\
\hline Admin & Kelola Data Guru & $\begin{array}{l}\text { Admin mengelola data guru yang dapat memproses input, edit } \\
\text { dan hapus }\end{array}$ \\
\hline Admin & Kelola Data SPP & $\begin{array}{l}\text { Admin mengelola data pembayaran SPP yang dapat } \\
\text { memproses input, edit dan hapus dari setiap siswa. }\end{array}$ \\
\hline Admin & Kelola Data Jadwal & Admin mengelola jadwal mata pelajaran. \\
\hline Admin & Kelola Data nilai & $\begin{array}{l}\text { Admin mengelola data-data nilai yang terdiri dari nilai tugas, } \\
\text { uts dan uas dari setiap siswa. }\end{array}$ \\
\hline Admin & Data Laporan & $\begin{array}{l}\text { Admin mengelola setiap laporan yang dapat di cetak untuk } \\
\text { dokumentasi }\end{array}$ \\
\hline Admin & Logout & $\begin{array}{l}\text { Admin dapat melakukan memproses logout untuk keluar dari } \\
\text { aplikasi }\end{array}$ \\
\hline
\end{tabular}

Deskripsi Use case diagram sistem usulan guru disajikan pada Tabel 9.

Tabel 9. Deskripsi Use Case Diagram Sistem Usulan Guru

\begin{tabular}{|l|l|l|}
\hline \multicolumn{1}{|c|}{ Aktor } & Nama Use Case & \multicolumn{1}{c|}{ Keterangan } \\
\hline Guru & Login & $\begin{array}{l}\text { Guru harus login dengan menggunakan id guru } \\
\text { untuk mengakses aplikasi. }\end{array}$ \\
\hline Guru & Data Jadwal & $\begin{array}{l}\text { Guru Dapat melihat dan mencetak jadwal mata } \\
\text { pelajaran. }\end{array}$ \\
\hline Guru & Data nilai & $\begin{array}{l}\text { Guru dapat menginput data-data nilai yang terdiri } \\
\text { dari nilai tugas, uts dan uas dari setiap siswa. }\end{array}$ \\
\hline Guru & Data Laporan & $\begin{array}{l}\text { Guru dapat melihat dan mencetak laporan data } \\
\text { jadwal mata pelajaran }\end{array}$ \\
\hline Guru & Logout & $\begin{array}{l}\text { Guru dapat melakukan memproses logout untuk } \\
\text { keluar dari aplikasi }\end{array}$ \\
\hline
\end{tabular}

Deskripsi Use case diagram sistem usulan siswa disajikan pada Tabel 10.

Tabel 10. Deskripsi Use Case Diagram Sistem Usulan Siswa

\begin{tabular}{|l|l|l|}
\hline \multicolumn{1}{|c|}{ Aktor } & \multicolumn{1}{c|}{ Nama Use Case } & \multicolumn{1}{c|}{ Keterangan } \\
\hline Siswa & Login & $\begin{array}{l}\text { Siswa harus login dengan menggunakan id } \\
\text { siswa untuk mengakses aplikasi. }\end{array}$ \\
\hline Siswa & Data Jadwal & $\begin{array}{l}\text { Siswa Dapat melihat dan mencetak jadwal } \\
\text { mata pelajaran. }\end{array}$ \\
\hline Siswa & Data SPP & Siswa dapat melihat hasil pembayaran SPP \\
\hline Siswa & Data Laporan & $\begin{array}{l}\text { Siswa dapat melihat dan mencetak laporan } \\
\text { data jadwal mata pelajaran }\end{array}$ \\
\hline Siswa & Logout & $\begin{array}{l}\text { Siswa dapat melakukan memproses logout } \\
\text { untuk keluar dari aplikasi }\end{array}$ \\
\hline
\end{tabular}

Deskripsi Use case diagram sistem usulan pimpinan disajikan pada Tabel 11. 
Tabel 11. Deskripsi Use Case Diagram Sistem Usulan Pimpinan

\begin{tabular}{|l|l|l|}
\hline \multicolumn{1}{|c|}{ Aktor } & Nama Use Case & \multicolumn{1}{|c|}{ Keterangan } \\
\hline Pimpinan & Login & $\begin{array}{l}\text { Pimpinan harus login dengan menggunakan } \\
\text { id pimpinan untuk mengakses aplikasi. }\end{array}$ \\
\hline Pimpinan & Data Laporan & $\begin{array}{l}\text { Pimpinan dapat melihat dan mencetak } \\
\text { semua data laporan }\end{array}$ \\
\hline Pimpinan & Logout & $\begin{array}{l}\text { Pimpinan dapat melakukan memproses } \\
\text { logout untuk keluar dari aplikasi }\end{array}$ \\
\hline
\end{tabular}

\subsubsection{Activity Diagram}

Activity diagram menunjukkan alur kerja dari aktivitas atau kegiatan yang dilakukan di dalam use case diagram. Activity diagram login disajikan pada Gambar 3.

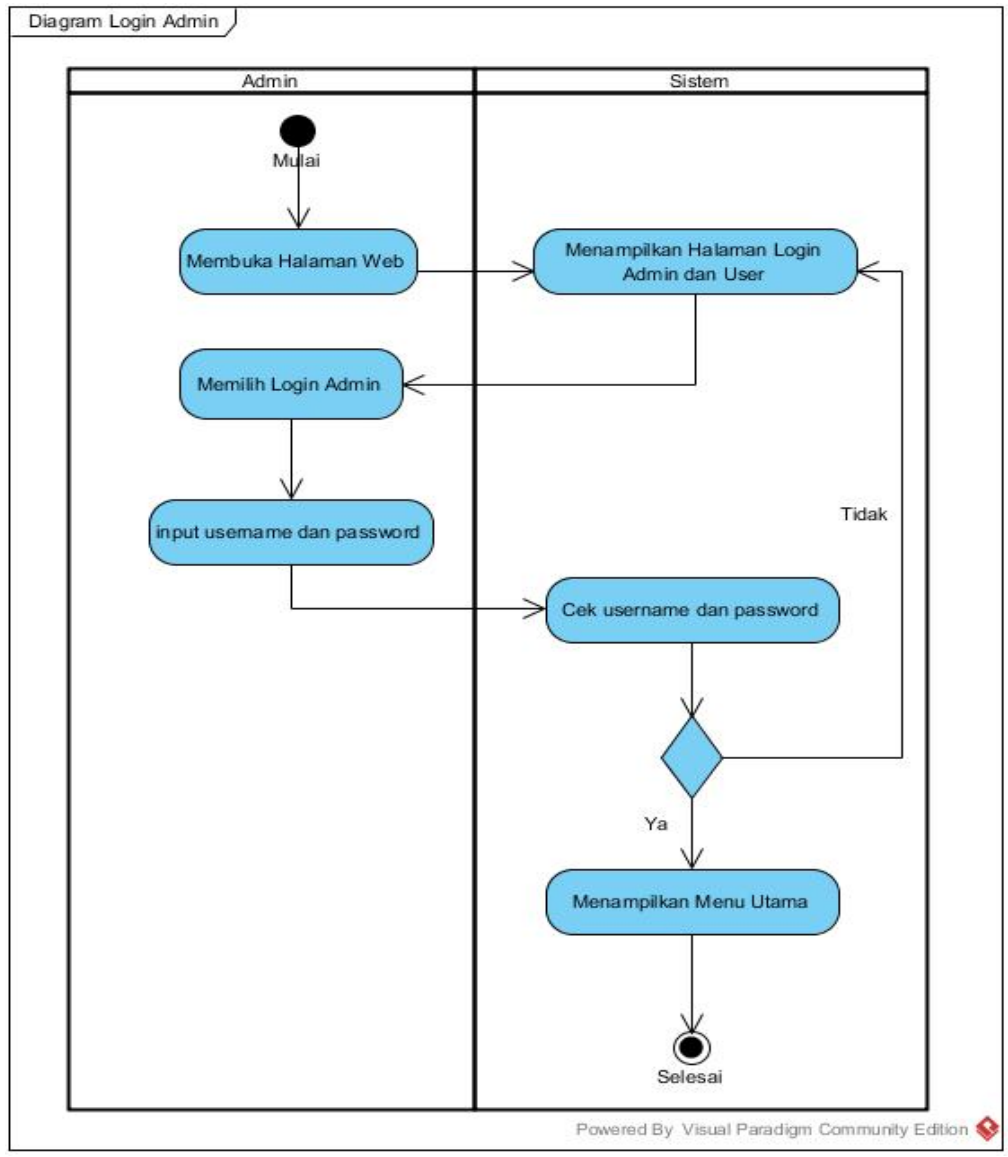

Gambar 3. Activity Diagram Login

Gambar 3 menjelaskan tentang alur login yang dilakukan oleh admin. Admin membuka aplikasi, sistem menampilkan aplikasi, kemudian admin input user name dan password, sistem menerima data dan melakukan proses simpan data ke database, jika proses gagal maka sistem akan kembali ke proses input user name dan password, jika proses berhasil maka akan masuk kesistem selesai. Selanjutnya Activity diagram siswa disajikan pada Gambar 4. 


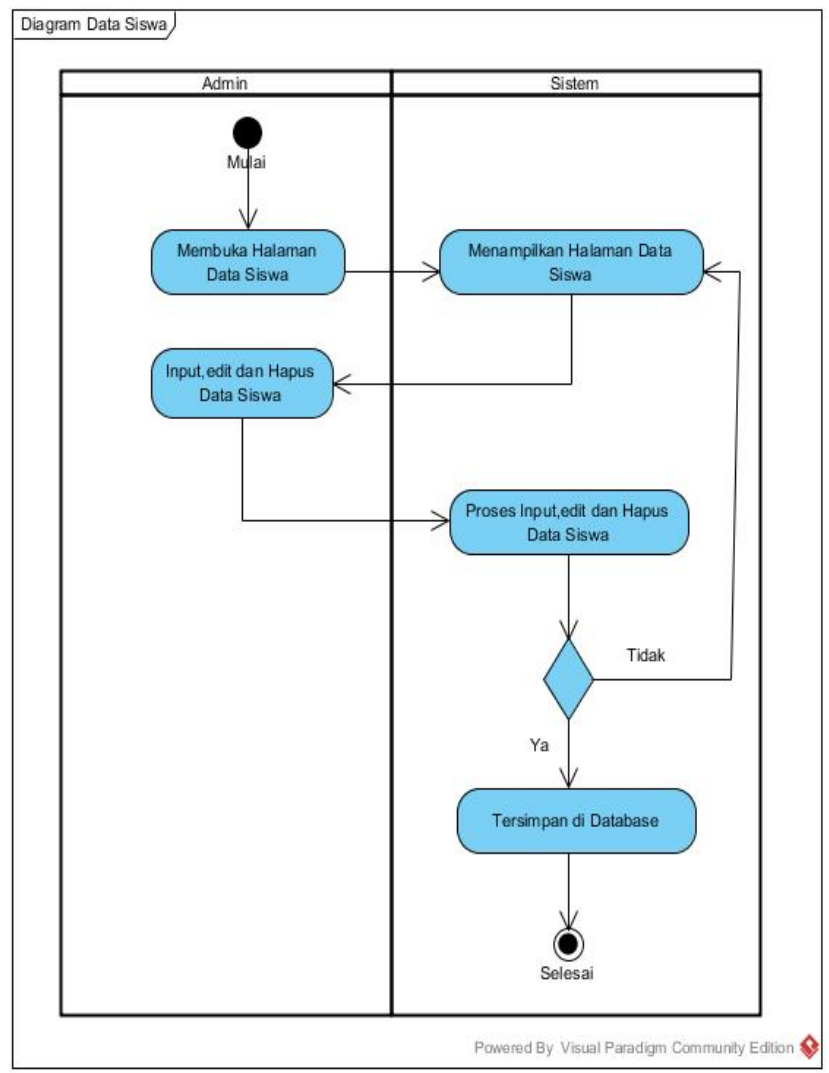

Gambar 4. Activity Diagram Siswa

Pada Gambar 4 menjelaskan tentang alur data siswa yang dilakukan oleh admin. Admin memilih menu siswa, sistem menampilkan halaman siswa, kemudian admin melakukan tambah, ubah dan hapus siswa, sistem menerima data dan melakukan proses simpan data ke database, jika proses gagal maka sistem akan kembali ke data siswa, jika proses berhasil maka sistem akan menyimpan data ke database dan proses selesai. Tahap selanjutnya adalah pembuatan Activity diagram guru.

Activity diagram guru menjelaskan tentang alur data guru yang dilakukan oleh admin. Admin memilih menu guru, sistem menampilkan halaman guru, kemudian admin melakukan tambah, ubah dan hapus guru, sistem menerima data dan melakukan proses simpan data ke database, jika proses gagal maka sistem akan kembali ke data guru, jika proses berhasil maka sistem akan menyimpan data ke database dan proses selesai.

Activity Diagram SPP menjelaskan tentang alur data SPP yang dilakukan oleh admin. Admin memilih menu SPP, sistem menampilkan halaman SPP, kemudian admin melakukan tambah, ubah dan hapus SPP, sistem menerima data dan melakukan proses simpan data ke database, jika proses gagal maka sistem akan kembali ke data SPP, jika proses berhasil maka sistem akan menyimpan data ke database dan proses selesai.

Activity diagram jadwal menjelaskan tentang alur data jadwal yang dilakukan oleh admin. Admin memilih menu jadwal, sistem menampilkan halaman jadwal, kemudian admin melakukan tambah, ubah dan hapus jadwal, sistem menerima data dan melakukan proses simpan data ke database, jika proses gagal maka sistem akan kembali ke data jadwal, jika proses berhasil maka sistem akan menyimpan data ke database dan proses selesai.

Activity diagram nilai menjelaskan tentang alur data nilai yang dilakukan oleh admin. Admin memilih menu nilai, sistem menampilkan halaman nilai, kemudian admin melakukan tambah, ubah dan hapus nilai, sistem menerima data dan melakukan proses simpan data ke database, jika proses gagal maka sistem akan kembali ke data nilai, jika proses berhasil maka sistem akan menyimpan data ke database dan proses selesai.

Activity diagram laporan menjelaskan tentang alur laporan yang dilakukan oleh admin. Admin memilih menu laporan, sistem menampilkan halaman data laporan, kemudian admin memilih laporan hari ini ataupun laporan per periode, sistem menerima data dan mencari data pada database, jika 
proses gagal maka sistem akan kembali ke menu laporan, jika proses berhasil maka sistem akan menampilkan data laporan .kemudian admin memilih cetak laporan, sistem memproses aksi cetak, jika proses berhasil maka sistem akan melakukan printout data laporan dan proses selesai.

Activity diagram logout menjelaskan tentang alur logout yang dilakukan oleh admin. Admin pilih menu logout, sistem melakukan proses logout dan kembali menampilkan halaman login, proses berhasil maka sistem selesai.

\subsubsection{Sequence Diagram}

Sequence diagram menggambarkan kelakuan objek. Beberapa sequence diagram pada program aplikasi sistem akademik. Sequence diagram login dan data siswa disajikan pada Gambar 5.

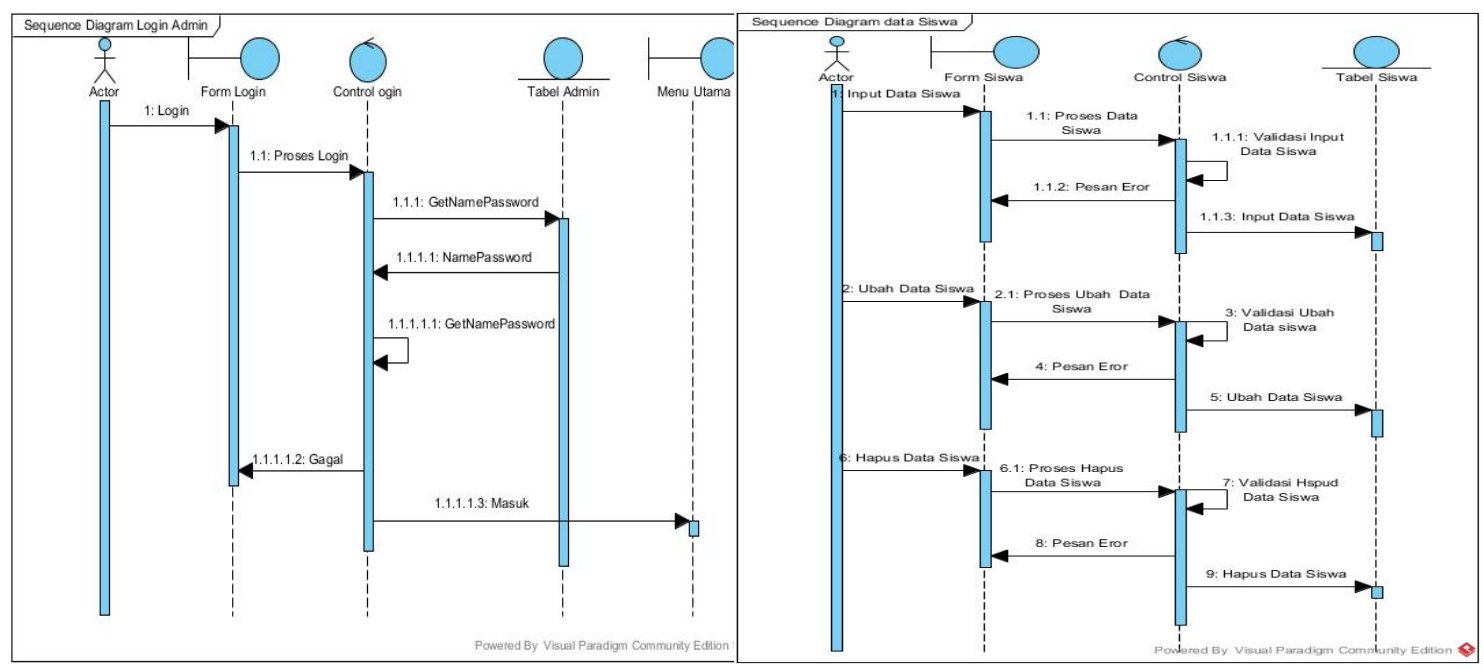

Gambar 5. Sequence Diagram Login dan Data Siswa

Sequence diagram yang lain adalah:

- Sequence diagram data guru dan SPP

- Sequence Diagram data jadwal dan nilai

- Sequence Diagram laporan dan logout

\subsection{Perancangan Antar Muka}

Perancangan menu digunakan untuk memudahkan dalam penelusuran program yang akan dibuat. Antarmuka halaman login disajikan pada Gambar 6.

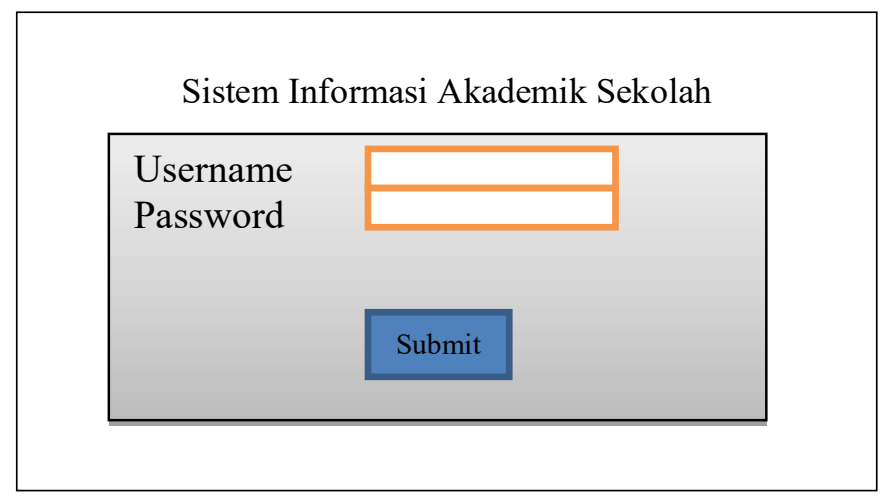

Gambar 6. Rancangan Struktur Menu Antarmuka Halaman Login 
Pada Gambar 6, mempuyai komponen-kompenen sebagai berikut:

1. TextFile (username dan password) digunakan untuk mengisi username dan password.

2. Button (submit) berfungsi untuk mengeksekusi data username dan password, sehingga dapat masuk ke dalam halaman utama sistem.

Antar muka halaman menu utama disajikan pada Gambar 7.

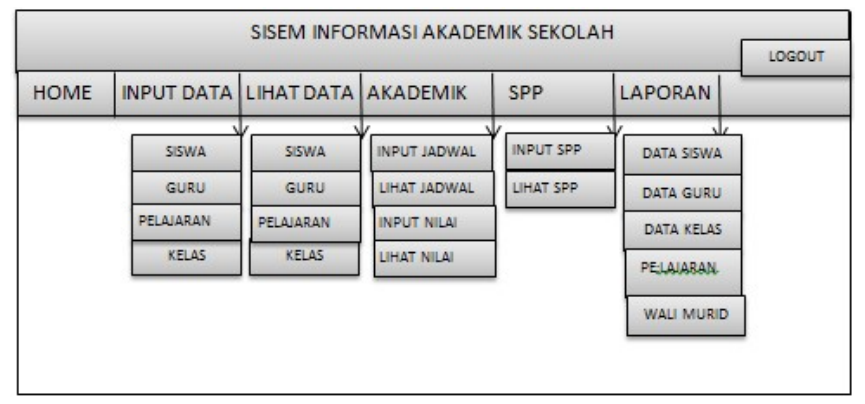

Gambar 7. Antar Muka Halaman Menu Utama

Pada halaman utama memiliki komponen-komponen sebagai berikut:

1. Menu item (input data) digunakan untuk menginput data-data siswa, guru, mata pelejaran dan kelas.

2. Мепи item (lihat data) digunakan untuk melihat data-data siswa, guru, mata pelajaran dan kelas.

3. Menu item (akademik) digunakan untuk menginput dan lihat data-data jadwal mata pelejaran dan nilai

4. Menu item (SPP) digunakan untuk menginput dan lihat data-data pembayaran SPP.

5. Menu item (laporan) digunakan untuk mengkonverter data-data dengan bentuk pdf dan excel, serta mencetak data laporan.

6. Мепи item (Logout) digunakan untuk keluar dari sistem

Antar muka halaman yang lain, adalah:

- Antar muka halaman input data

- Antar muka halaman lihat data

- Antar muka halaman laporan

Pada halaman input data siswa diatas mempunyai kompenen-komponen yang terdiri dari:

1. Text field (Nis) digunakan untuk memasukkan Nis siswa.

2. Text field (Nama) digunakan untuk memasukkan Nama siswa.

3. Text field (password) digunakan untuk memasukkan password siswa.

4. Combo box (kelas) digunakan untuk memilih kelas yang ada dalam combo box tersebut.

5. Text area (alamat) digunakan untuk memasukkan alamat siswa.

6. Button (simpan data) yang berfungsi mengeksekusi data yang di input, sehingga tersimpan ke dalam database sistem.

7. Button (reset) yang berfungsi menghapus data yang telah di ketik pada kolom Text field.

Antar muka halaman lihat data digunakan untuk melihat data-data siswa, guru, mata pelejaran, kelas, mata pelajaran, nilai dan SPP. Pada halaman lihat data terdapat kompenen-komponen yang terdiri dari:

1. Pada kolom tabel pilihan digunakan untuk merubah dan menghapus data.

2. Combo box (all Colums) digunakan untuk memilih berdasarkan Nama yang ada dalam combo box tersebut.

3. View all digunakan untuk menampikan semua halaman tabel.

Pada halaman laporan mempunyai kompenen-komponen yang terdiri dari:

1. Button (Copy, Excel, dan Pdf) digunakan untuk mengkonvert data dalam penyimpanan.

2. Button (Print) digunakan untuk mencetak data. 


\section{Implementasi dan Pengujian}

\subsection{Implementasi Sistem}

Implementasi sistem merupakan tahap akhir ketika sistem siap untuk dioperasikan pada keadaan sebenarnya, sehingga akan diketahui sistem yang dibuat benar-benar dapat menghasilkan tujuan yang diinginkan oleh peneliti. Sebelum aplikasi diterapkan dan diimplementasikan, maka program harus bebas dari kesalahan (error free) guna memastikan sistem tersebut benar-benar dapat berjalan secara baik. Kesalahan program yang mungkin terjadi antara lain: kesalahan penulisan bahasa, kesalahan sewaktu proses atau kesalahan logika. Setelah aplikasi bebas dari kesalahan, aplikasi diuji dengan memasukkan data untuk diproses.

\subsubsection{Implementasi Perangkat Keras}

Spesifikasi hardware perangkat keras yang digunakan peneliti disajikan pada Tabel 12.

Tabel 12. Spesifikasi Perangkat Keras

\begin{tabular}{|l|l|}
\hline Prosesor & Intel Core i3-4005U, 1.7GHz \\
\hline Memory & 2GB \\
\hline Graphics & HD Graphics Family \\
\hline Storage & HDD 500GB \\
\hline LCD Display & 11.6 LED Display \\
\hline Keyboard \& Mouse & Standard \\
\hline
\end{tabular}

\subsubsection{Implementasi Perangkat Lunak}

Penerapan sistem aplikasi edukasi berbasis Web membutuhkan perangkat lunak (software) pendukung maupun sistem operasi untuk menjalankan aplikasi tersebut. Adapun perangkat lunak maupun sistem operasi yang dibutuhkan dalam perancangan aplikasi ini disajikan pada Tabel 13.

Tabel 13. Spesifikasi Perangkat Lunak

\begin{tabular}{|l|l|}
\hline Sistem operasi notebook & Windows 7 Professional 64 Bit \\
\hline Aplikasi permodelan & Unified Modeling Language version 10.1 \\
\hline Aplikasi pengolah kata & Microsoft Office 2007 \\
\hline Aplikasi perancangan & Notepad ++32 bit \\
\hline Aplikasi design & Adobe Photoshop cs 3 \\
\hline
\end{tabular}

\subsubsection{Implementasi Antarmuka}

Antarmuka adalah komponen sistem yang bersentuhan langsung dengan pengguna. Implementasi antar muka sistem merupakan realisasi desain tampilan antar muka dari setiap menu yang telah PHP. Tampilan halaman login disajikan pada Gambar 8.

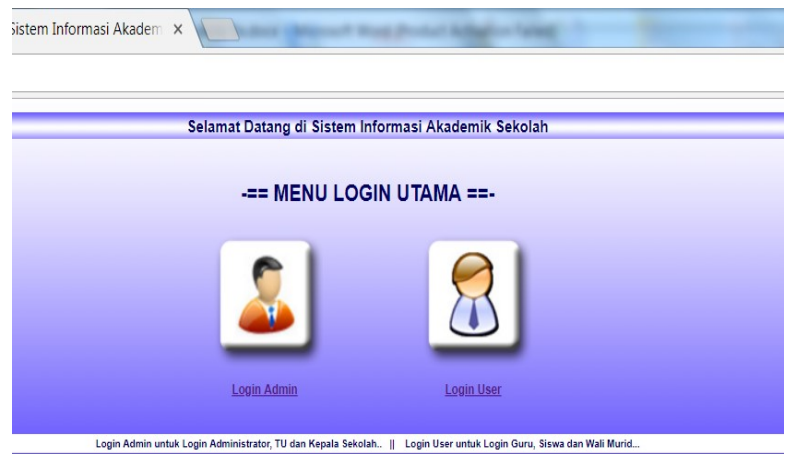

Gambar 8. Tampilan Halaman Login 


\subsection{Pengujian Sistem}

Pada tahap ini akan dilakukan pengujian sistem untuk memeriksa apakah suatu perangkat lunak yang dihasilkan sudah dapat dijalankan sesuai dengan kriteria tertentu. Pengujian sistem merupakan hal terpenting yang bertujuan untuk menentukan kesalahan-kesalahan atau kekurangan-kekurangan pada perangkat lunak yang diuji. Adapun teknik pengujian sistem pendukung keputusan promosi jabatan yaitu dengan pengujian black box. Pengujian Black Box berfokus pada persyaratan fungsional perangkat lunak. Pengujian berikut dilakukan guna memeriksa secara singkat untuk memeriksa tingkat keakuratan sistem.

\subsubsection{Pengujian Black Box}

Pengujian sistem pendukung keputusan promosi jabatan ini menggunakan data uji berupa data input dari admin sebagai pengguna pada sistem yang telah dibuat. Rancangan pengujian disajikan pada Tabel 14.

Tabel 14. Rancangan Pengujian

\begin{tabular}{|l|l|}
\hline \multicolumn{1}{|c|}{ Item Uji } & \multicolumn{1}{|c|}{ Jenis Pengujian } \\
\hline Login & Black Box \\
\hline $\begin{array}{l}\text { Pengolahan password, profil, kelas, tiket, } \\
\text { jadawal, pesanan tiket, cara pemesanan, laporan. }\end{array}$ & Black Box \\
\hline $\begin{array}{l}\text { Pengolahan perubahan data pada saat proses } \\
\text { edit data }\end{array}$ & Black Box \\
\hline $\begin{array}{l}\text { Pengolahan hapus data pada saat proses delete } \\
\text { data }\end{array}$ & Black Box \\
\hline
\end{tabular}

Berdasarkan tabel rancangan pengujian yang telah disusun, maka dapat dilakukan pengujian login yang disajikan pada Tabel 15.

Tabel 15. Pengujian Login

\begin{tabular}{|l|l|l|l|l|}
\hline No & $\begin{array}{c}\text { Nama } \\
\text { Modul }\end{array}$ & \multicolumn{1}{|c|}{ Tes Fungsional } & Hasil yang Diharapkan & \multicolumn{1}{|c|}{$\begin{array}{c}\text { Status/Catatan } \\
\text { Error }\end{array}$} \\
\hline 1 & Login & $\begin{array}{l}\text { Input username dan password } \\
\text { yang terdaftar di basis data }\end{array}$ & $\begin{array}{l}\text { Berhasil masuk dan diarahkan } \\
\text { ke menu utama (home) }\end{array}$ & $\begin{array}{l}\text { Sesuai yang } \\
\text { diharapkan }\end{array}$ \\
\hline 2 & Login & $\begin{array}{l}\text { Input username dan password } \\
\text { yang tidak terdaftar di basis } \\
\text { data }\end{array}$ & $\begin{array}{l}\text { Gagal login dan ada } \\
\text { peringatan'LOGIN GAGAL! } \\
\text { Username atau Password Anda } \\
\text { tidak benar. } \\
\text { Atau account Anda sedang } \\
\text { diblokir. } \\
\text { ULANGI LAGI }\end{array}$ & $\begin{array}{l}\text { Sesuai yang } \\
\text { diharapkan }\end{array}$ \\
\hline
\end{tabular}

Tahap selanjutnya yaitu pengujian menu input data. Pengujian menu input data disajikan pada Tabel 16. 
Tabel 16. Pengujian Menu Input Data

\begin{tabular}{|c|l|l|l|l|}
\hline No & Nama Modul & \multicolumn{1}{|c|}{ Tes Fungsional } & \multicolumn{1}{|c|}{$\begin{array}{c}\text { Hasil yang } \\
\text { Diharapkan }\end{array}$} & Status/Catatan Error \\
\hline 1 & Input Data & $\begin{array}{l}\text { Pilih menu input } \\
\text { data }\end{array}$ & $\begin{array}{l}\text { Data tersimpan pada } \\
\text { database }\end{array}$ & Sesuai yang diharapkan \\
\hline 2 & Edit Data & $\begin{array}{l}\text { Klik edit pada } \\
\text { lambang edit }\end{array}$ & $\begin{array}{l}\text { Menampilkan form } \\
\text { edit }\end{array}$ & Sesuai yang diharapkan \\
\hline 3 & Hapus Data & $\begin{array}{l}\text { Klik Hapus pada } \\
\text { lambang hapus }\end{array}$ & $\begin{array}{l}\text { Data dihapus dari } \\
\text { database }\end{array}$ & Sesuai yang diharapkan \\
\hline
\end{tabular}

Tahap pengujian Black Box selanjutnya yaitu pengujian menu laporan yang disajikan pada Tabel 17.

Tabel 17. Pengujian Menu Laporan

\begin{tabular}{|l|l|l|l|l|}
\hline No & \multicolumn{1}{|c|}{ Nama Modul } & \multicolumn{1}{|c|}{ Tes Fungsional } & Hasil yang diharapkan & \multicolumn{1}{|c|}{$\begin{array}{c}\text { Status/Catatan } \\
\text { Error }\end{array}$} \\
\hline 1 & Laporan & $\begin{array}{l}\text { Pilih menu-menu data } \\
\text { laporan }\end{array}$ & $\begin{array}{l}\text { Menampilkan data-data } \\
\text { laporan }\end{array}$ & $\begin{array}{l}\text { Sesuai yang } \\
\text { diharapkan }\end{array}$ \\
\hline 2 & Cetak Laporan & Pilih print & Data berhasil di print & $\begin{array}{l}\text { Sesuai yang } \\
\text { diharapkan }\end{array}$ \\
\hline
\end{tabular}

\subsubsection{Pengujian White Box}

Pengujian White Box bertujuan untuk memperlihatkan cara kerja dari aplikasi. Berikut salah satu contoh pengujian White Box disajikan pada Gambar 9.

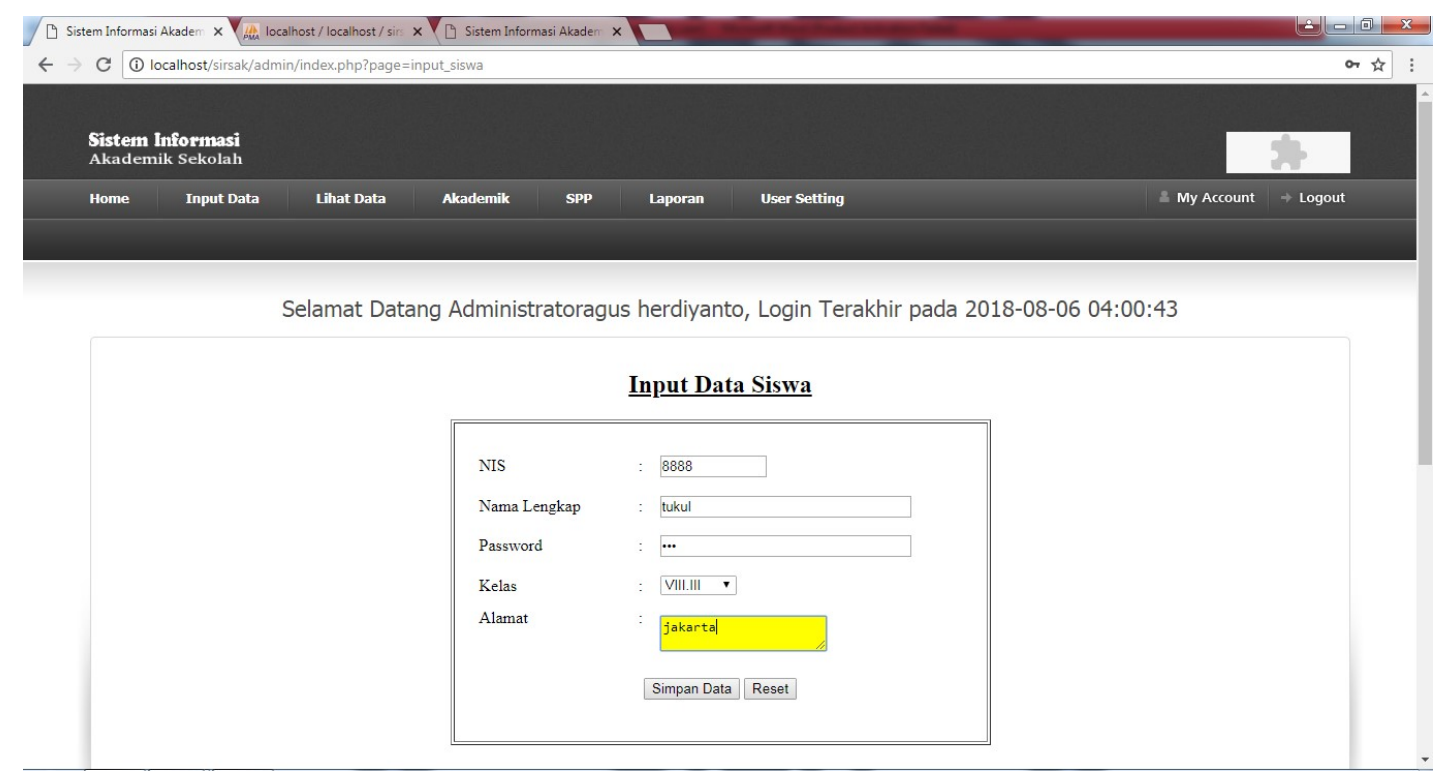

Gambar 9. Pengujian White Box

Hasil pengujian White Box terlihat jelas jika menginput biodata siswa tanpa mengisi kolom nis sistem akan menolak dan menampikan notification. 


\section{Kesimpulan}

Berdasarkan analisis masalah sistem informasi akademik ini, maka hasil dari penelitian ini dapat diambil kesimpulan bahwa dengan adanya sistem informasi akademik ini diharapkan dapat mempermudah pihak guru dan orang tua wali serta murid untuk mencari data Sekolah Menengah Pertama Negeri I Tajurhalang. Adanya sistem informasi akademik ini dapat lebih akurat dalam mendapatkan data dan informasi yang diperoleh. Sistem informasi akademik ini dapat mempermudah dalam pengerjaan dalam mengolah data dan mengurangi tingkat kesalahan dalam perhitungan database siswa dan guru sehingga informasi yang ada dapat sesuai.

\section{Daftar Pustaka}

[1] M. Susanti, "Perancangan Sistem Informasi Akademik Berbasis Web Pada Smk Pasar Minggu," Jurnal Informatika, vol. 3, no. 1, pp. 91-99, 2016.

[2] D. Fauzi, Perancangan dan Implementasi Sistem Informasi Akademik Sekolah dengan Metode Structured Analysis and Design Technique (SADT). Riau: UIN Sultan Syarif Kasim Riau, 2010.

[3] Yakub, Pengantar Sistem informasi. Yogyakarta: Graha Ilmu. 2012.

[4] D.C. Ericko, Perancangan Sistem Informasi Berbasis Web Pada Sekolah SMK Kartika 1-I Medan. Medan: Universitas Sumatera Utara, 2009.

[5] A. Syarif, E. Sovia, and M. Abulwafa, "Perancangan Content Management System (CMS) Dengan Studi Kasus E-Bisnis Pada Toko Alya Gorden," Jurnal KomTekInfo, vol.2, no. 1, pp. 79-90, 2015.

[6] A. Syarif. Perancangan Sistem Informasi Berbasis Website Pada Sekolah SMK Negeri 1 Sigala-gala. Medan: Universitas Sumatera Utara, 2009.

[7] M. Sukarno, Membangun Website Dinamis Interaktif dengan PHP-MySQL. Jakarta: Eska Media Press, 2006.

[8] A. H. Fatta, Analisis dan Perancangan Sistem Informasi. Yogyakarta: Andi Offset, 2007.

[9] Jogiyanto, Pengembangan Media Pembelajaran Berbasis Teknologi Informasi. Malang: Universitas Brawijaya, 2012.

[10] Suendri, "Implementasi Diagram UML (Unified Modelling Language) pada Perancangan Sistem Informasi Remunerasi Dosen dengan Database Oracle (Studi Kasus: UIN Sumatera Utara Medan)," Algoritma, vol. 3, no. 1, pp. 1-9. 2018. 